\title{
KEPLER Y EL TEOREMA FundAMENTAL DE LA ÓPTICA
}

KEPLER AND THE FUNDAMENTAL THEOREM OF OPTICS

\author{
CARlos Alberto Cardona \\ Universidad del Rosario, Bogotá, ColOMBIA \\ carlos.cardona@urosario.edu.co
}

\begin{abstract}
The article discusses the arguments with which Kepler demonstrates what we will call the fundamental theorem of optics. According to this theorem, a homocentric beam of light that passes through a transparent sphere, provided that the amplitude of the beam is small, is concentrated again at one point on the other side of the sphere. We show how the philosopher, using geometric analogies as paper tools and despite relying on both an imprecise law for refraction and certain approaches, came to an outcome that tradition incorporated as promising. Indeed, modern tradition incorporated the theorem by correcting what, in his view, were methodological errors.
\end{abstract}

Keywords: law of refraction $\bullet$ images $\bullet$ eye $\bullet$ camera obscura

\section{Introducción}

La obra publicada de Johannes Kepler (1571-1630) es una mina de oro para historiadores y filósofos de la ciencia porque, entre otras razones, el autor no oculta la lógica del descubrimiento. Sus escritos exhiben generosamente los intrincados caminos de la heurística que lleva a sus resultados. Se conoce, por ejemplo, que el autor llegó a las tres leyes de la mecánica celeste, que llevan su nombre, no solo gracias a los datos acopiados por Tycho Brahe (1546-1601), sino también al gran esfuerzo por acoplar la información con una mecánica del cielo ajustada a ciertos principios aristotélicos leídos bajo la influencia del neoplatonismo. ${ }^{1}$ La astronomía moderna supo valorar los resultados del pensador alemán, pero tuvo que asimilarlos a una nueva mecánica celeste. Isaac Newton (1642-1727) ofreció posteriormente nuevas demostraciones de tales leyes a partir de supuestos completamente diferentes a los de Kepler.

Kepler tenía gran aprecio por las analogías. Buena parte de su heurística se apoya en seguir las pistas que le ofrecen ciertas analogías cuidadosamente seleccionadas. ${ }^{2}$ Charles Sanders Peirce (1839-1914) ofreció una interesante y precisa descripción de la metodología kepleriana:

Su admirable método de pensar consiste en formar, en su mente, un diagrama o bosquejo de representación del intrincado estado de cosas ante él; 
omitiendo todo lo que fuese accidental, mientras se retiene lo que es esencial, observa las relaciones sugestivas entre las partes del diagrama, realiza diversos experimentos sobre este o sobre los objetos naturales y toma nota de los resultados (1985, p.294).

Los diagramas que menciona Peirce desempeñan el papel de herramientas que conducen o controlan los razonamientos del filósofo. Como sugiere Arianna Borelli, tales diagramas fungen como "herramientas de papel" (2017, pp.60-61). Los diagramas, en cierto sentido, anticipan las características del fenómeno a estudiar. Valeria Giardino defiende que los diagramas, utilizados como herramientas cognitivas, no son simplemente una imagen sinóptica del objeto matemático en cuestión, sino que sugieren, además, algún tipo de intervención racional (2017, p.500). La aplicación de diagramas en la heurística de Kepler no se reduce a ilustrar un resultado, sino que resulta esencial en la creación y evaluación del mismo. Pretendo mostrar que los diagramas de Kepler, incorporados en su heurística, son ejemplares de las valoraciones de Giardino y Borelli.

Como advierte Albrecht Heeffer "Aunque los diagramas obviamente recurren a nuestras capacidades visuales, no se limitan a meras acciones visuales, sino que implican operaciones mentales cinéticas" (2017, pp.145-46). Algunos elementos de las operaciones cinéticas que demandan los diagramas de Kepler quedarán más claros si el lector sigue las modelaciones dinámicas que acompañan algunas de las figuras. Si la figura tiene modelación, en paréntesis cuadrados aparece el enlace que lleva a ella y se informa acerca de los elementos geométricos que el lector puede modificar a su antojo.

En el artículo seguimos con cuidado los intrincados caminos de la heurística que llevaron al pensador a uno de los resultados más estimados de la óptica moderna. Mostramos cómo, a pesar de apoyarse en una ley imprecisa para la refracción y confiar en ciertas aproximaciones que suponen intervenciones sobre diagramas, supo compensar los errores, omitiendo lo accidental mientras retenía lo esencial, para conseguir que los diagramas o bosquejos le llevaran en una dirección prometedora.

Cuando Kepler llegó a la corte de Praga, recibió la triste noticia de la muerte de Tycho Brahe, justo en el momento en el que empezaba a conformarse la alianza estratégica entre dos gigantes. Tycho murió en 1601. Los familiares del astrónomo, herederos de sus pertenencias, iniciaron una agria disputa con el emperador y conservaron por un tiempo la custodia de los instrumentos y de los datos acopiados por el investigador a lo largo de toda su vida. Esta disputa obligó a una reformulación del plan de trabajo de Kepler, quien heredó el cargo de matemático imperial. En una carta de 1602 dirigida a su amigo Herwart von Hohenburg (1553-1622), Kepler explica:

A causa de que mis tareas se han puesto en duda, he asumido la obligación de ocuparme de dos trabajos. El primero estará listo en la Pascua [1603] y 
se ocupará de comentarios sobre la teoría de Marte [... ]; el segundo, que estará finalizado en 8 semanas, es la parte óptica de la astronomía. (Citado en Voelkel, 2001, p.147).

El primer trabajo dio origen a la Astronomia nova; el segundo, Ad Vitelionem paralipomena, quibus Astronomiæ pars optica traditur (1604), en adelante Paralipomena, reunió las más importantes contribuciones al estudio de la óptica.

Uno de los resultados más valiosos de la óptica moderna consiste en concebir la estructura ocular a la manera de una cámara obscura. El orificio de la cámara hace las veces de la pupila; el lente que se dispone a la entrada simula el cristalino y la pantalla posterior funge como la retina. Durante el siglo XX, el recurso fue sometido a una severa crítica y se le hizo responsable de la emergencia del mito del teatro interior. Al margen de las críticas, el uso del recurso facilitó una gran cantidad de hallazgos tanto empíricos como teóricos a propósito del estudio de la dinámica del sistema ocular.

Si bien antes del siglo XVII hay una copiosa literatura centrada en la perplejidad que producen las imágenes observadas a través de agujeros, sólo después de la publicación de los Paralipomena, se acogió con convicción el símil de la cámara obscura como un recurso para estudiar el funcionamiento ocular. La aceptación de la propuesta en su forma madura tuvo que enfrentar tres dificultades poderosas, todas ellas resueltas en el tratado de Kepler: ofrecer un protocolo matemático para anticipar cómo se forman las imágenes de un objeto luminoso cuando se recogen sobre una pantalla en una cámara que contiene un pequeño agujero; anticipar el comportamiento de la luz cuando atraviesa una lente esférica; y reconocer el protagonismo de la retina en la recepción de copias pictóricas de los objetos externos.

Se puede discutir si fue la analogía de la cámara la que condujo a la imagen retiniana o si fue, más bien, el reconocimiento de la imagen retiniana lo que contribuyó a darle fuerza a la analogía. Stephen Straker defiende la primera perspectiva (1971, p.453). En el artículo muestro que la propuesta de una pintura retiniana, en parte, se fortalece a partir de un cuidadoso seguimiento de los trayectos imaginados para la luz. ${ }^{3}$ No obstante, una comprensión completa del proyecto de Kepler demanda considerar la fina distinción que traza el autor entre pintura retiniana e imagen mental. ${ }^{4}$ Estos dos elementos acoplados le dan fuerza al símil de la cámara obscura. David Lindberg señala que si bien no contamos con herramientas para decidir finalmente qué aportó a qué, no fue la analogía la base definitiva para construir la teoría kepleriana de la visión (1976, p.205-206). Lindberg se opone a la segunda alternativa aduciendo que Kepler acogió las estructuras teóricas dadas por los perspectivistas clásicos. En ese orden de ideas, Kepler es, a los ojos de Lindberg, la figura que cierra la tradición perspectivista (1976, p.207). Si bien, el núcleo del artículo no tiene que ver con la distinción pintura/imagen, se puede aducir, como lo hacen R. Chen-Morris 
(2009) y A. Malet (1990), que la distinción introduce una ruptura central con la tradición óptica.

La solución a la segunda dificultad puede, para su análisis, dividirse en dos problemas independientes: (i) hallar una ley cuantitativa confiable que subsuma el comportamiento de la luz cuando pasa de un medio a otro (refracción) y (ii) aplicar dicha ley para el caso que se restringe al paso de la luz a través de una lente esférica. El segundo de estos problemas llevó a Kepler a defender un resultado que, por la importancia que tiene en relación con las pesquisas posteriores, denominaremos Teorema Fundamental de la Óptica. Kepler presentó el teorema en los siguientes términos:

Yo digo que esta pintura [la que se recoge en la retina] consiste de tantos pares de conos [conorum] como puntos hay en el objeto visto. Estos pares tienen la misma base, la amplitud del humor cristalino, o una pequeña parte de él, así que uno de los conos está dispuesto con su vértice en el punto visto y su base en el cristalino (aunque ésta resulte ligeramente afectada por la refracción que se da en la córnea), en tanto que el otro, tiene la base en el cristalino, semejante al primer cono, mientras el vértice, en algún punto de la pintura, alcanza la superficie de la retina después de someterse a la refracción originada desde el cristalino. (Paralipomena, V, p. 182; GW, p.153)

El sentido del teorema se hace más claro si nos valemos de un diagrama (Figura 1). Sea $A$ un punto radiante ubicado sobre el eje ocular. $A$ radia luz en todas las direcciones; en particular, en el cono que tiene como base el fragmento $B B^{\prime}$ que se acerca a los bordes de la pupila.

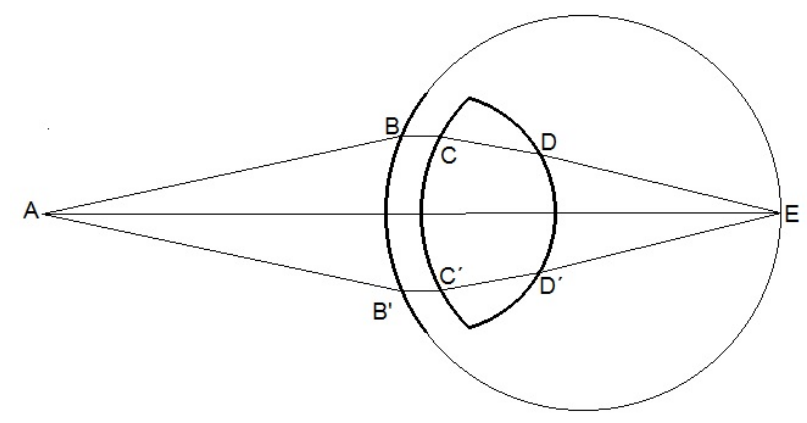

Figura 1: Despliegues de conos de luz en el ojo

Entre la córnea y la cara anterior del cristalino, la luz sufre una primera refracción. En este trayecto, muy corto, los rayos se pliegan levemente hacia la normal. Así entonces, los rayos externos se desplazan de $B$ a $C$ y de $B^{\prime}$ a $C^{\prime}$. Al ingresar al siguiente humor, estos rayos sufren una refracción más intensa, se acercan mutuamente hasta reducirse a la región más estrecha $D D^{\prime}$ en la parte posterior del cristalino. Dado que 
el humor vítreo es menos denso ópticamente que el cristalino, se provoca una nueva refracción que acerca los rayos hacia la tangente a la cara posterior del cristalino en los puntos de incidencia. Los nuevos rayos convergen hacia el eje del globo ocular y se reúnen precisamente en el punto $E$ sobre la retina.

Nos vamos a ocupar en el artículo de la compleja estructura del argumento kepleriano que conduce a la defensa del teorema. Para ello dividiremos el texto en cuatro apartados. Primero, sin entrar en detalles, nos detenemos en la formación de imágenes a través de agujeros. Segundo, sin detenernos tampoco, presentamos la ley de la refracción de la que se valió Kepler para la demostración del teorema. Tercero, atentos a los detalles, mostramos cómo es posible derivar el teorema a partir de la ley mencionada y señalamos tanto las aproximaciones que implican razonamientos cinéticos con diagramas, como los errores a la luz de la tradición moderna. Por último, hacemos alusión a dos demostraciones modernas para mostrar que así como Newton corrigió las maniobras de Kepler para incorporar las leyes del movimiento planetario a la nueva física, los investigadores modernos hicieron lo propio para incorporar el teorema fundamental a la nueva óptica. ${ }^{5}$

\section{El problema de los agujeros}

Dos hechos especiales dirigieron la atención de Kepler hacia sus investigaciones en óptica: el pronunciado desplazamiento al color rojo que exhibe la Luna durante un eclipse lunar y los cálculos que Tycho Brahe hizo a propósito del diámetro de la Luna valiéndose de las imágenes contempladas a través de cámaras con orificios muy pequeños. Tycho estableció que el diámetro de la Luna durante un eclipse solar se reduce una quinta parte en relación con el diámetro observado en Luna llena. ${ }^{6}$ Este paradójico resultado, que de hecho implicaba que era imposible que pudiera darse un eclipse total, indujo a Kepler a pensar que había un error importante en los cálculos; error que exigía una clarificación completa de la formación de imágenes ópticas en esta clase de dispositivos.

En el tratado de óptica Kitāb al-Manāzir (De Aspectibus), en adelante Aspectibus, el filósofo árabe Alhacén (965-1040), se sugiere un diseño experimental a partir de un conjunto de velas encendidas que dejan ver sobre una pantalla en una cámara a la que se le ha practicado un diminuto orificio (Aspectibus, I, 6.85). Con el diseño, Alhacén quería probar que las especies — semejanzas de los objetos- no se obstaculizan mutuamente en su tránsito cuando se ven obligadas a atravesar pequeños agujeros. El estudio de la formación de imágenes a través de agujeros demanda resolver un problema sugerido por Aristóteles: «¿Por qué el Sol, cuando pasa a través de cuadriláteros, no forma figuras rectilíneas sino círculos?» (2004, 911b). Si frente al Sol interponemos una pared con un pequeño agujero cuyos bordes definen un po- 
lígono y buscamos al otro lado de la pared la imagen que forma el astro sobre una pantalla, sorprende que a una distancia adecuada observemos una imagen circular en lugar de la figura del polígono que delimita al agujero. Fueron varios los intentos de destacados pensadores encaminados a resolver el problema antes de que Kepler ofreciera la solución definitiva. ${ }^{7}$

La idea básica de Kepler para resolver la dificultad, obviando los detalles matemáticos, es la siguiente (Paralipomena, pp. 55-71; GW, ${ }^{8}$ pp.46-61): desde cada uno de los puntos del objeto luminoso emanan pirámides de multiplicación; éstas, al ser obstaculizadas por la pared que contiene el agujero, proyectan, sobre el fondo, una imagen que reproduce la forma del agujero. Al iterar el proceso con cada uno de los puntos de la cara visible del objeto, se consigue una rapsodia de contrastes sombrailuminación ajustada al siguiente patrón: una silueta que copia una forma invertida del objeto, bordeada por un gradiente de sombras que perfilan imágenes derechas del agujero. Si el agujero es muy pequeño, las sombras que bordean la silueta tienden a desaparecer; si el agujero es de tamaño considerable y la pantalla está muy cerca, la figura dominante es la del agujero, bordeada de gradientes de iluminación que perfilan la silueta del objeto. Un seguimiento del uso de diagramas en las pesquisas de Kepler al respecto pone en evidencia, también, las tesis que queremos defender en el artículo.

A comienzos del siglo XX, el mundo occidental conoció, gracias a la traducción al alemán, un estudio clásico detallado de la cámara obscura como un instrumento de observación de los eclipses. El estudio proviene de Alhacén. Este tratado puede reportarse como el primer estudio matemático cuidadoso de la formación de imágenes en un dispositivo como la cámara obscura. Algunos de los resultados del escrito coinciden con los análisis de Kepler. No obstante, no hay indicio de que Kepler tuviese conocimiento alguno de dicho trabajo (Straker, 1981, p.176 n. 11). ${ }^{9}$

Si la comparación del ojo con una cámara obscura es razonable, las pinturas recogidas en la retina tendrían que acompañarse de tenues sombras provocadas por la proyección de la abertura de la pupila, como se desprende de la teoría de Kepler. En el siglo XVII no había forma de poner en evidencia esa expectativa. A mediados del siglo XIX, Herman von Helmholtz (1821-1894), el inventor y creador del oftalmoscopio, probó que las pinturas retinianas, efectivamente, están bordeadas por círculos difusos provocados por la proyección de la pupila (2005 [1909], vol.1, pp.121-32).

\section{Ley de la refracción}

Kepler era consciente de que sólo al contar con una ley precisa para la refracción, podría descontar los efectos engañosos en las observaciones astronómicas como resultado de la modificación de los trayectos de la luz al pasar del éter celeste al aire 
que circunda la Tierra y al atravesar las esferas cristalinas del ojo. El científico se empeñó en hallar un instrumento matemático — diagrama- que pudiera anteponer como analogía. Así las cosas, al manipular las variables del instrumento conforme a una regla, se podría anticipar el ángulo de refracción esperado para cada ángulo de incidencia posible. Se ensayaron tres familias de analogías, cada una con varios ejemplares como alternativas. Las dos primeras fallaron al contrastar las expectativas teóricas con la información empírica disponible para la transición de la luz desde el aire al agua. La tercera familia condujo a un resultado que, aunque era muy diferente a la ley de Snell-Descartes, coincidía con la información empírica para ángulos pequeños.

A propósito de la información empírica disponible, Kepler se valió de la tabla que Witelo (1230-1314) transcribió de Ptolomeo (100-170). La tabla de Witelo (Tabla 1) presenta los ángulos de incidencia y refracción medidos con respecto a la normal y presenta también la desviación del rayo refractado con respecto al incidente. ${ }^{10}$

\begin{tabular}{ccc} 
Ángulo de incidencia & Desviación & Ángulo de refracción \\
\hline 10 & $2^{0} 5^{\prime}$ & $7^{0} 45^{\prime}$ \\
20 & $4^{0} 30^{\prime}$ & $15^{0} 30^{\prime}$ \\
30 & $7^{0} 30^{\prime}$ & $22^{0} 30^{\prime}$ \\
40 & $11^{0}$ & $29^{0}$ \\
50 & $15^{0}$ & $35^{0}$ \\
60 & $19^{0} 30^{\prime}$ & $40^{0} 30^{\prime}$ \\
70 & $24^{0} 30^{\prime}$ & $45^{0} 30^{\prime}$ \\
80 & 30 & $50^{\circ}$ \\
\hline
\end{tabular}

Tabla 1. Datos de Witelo

Fuente: Los datos se encuentran en Risner, 1572, X, 8, p.412 y son citados por Kepler, con las correcciones señaladas en la nota anterior, en Paralipomena, p.128, GW, p.109.

Primera familia de analogías. Kepler asumió que las variables a tener en cuenta en la ley de la refracción debían ser la diferencia entre las densidades ópticas de los medios y la magnitud del ángulo de incidencia (Paralipomena, IV, p.96, GW, p.81). Los ejemplares de los diagramas empleados se ajustan al siguiente esquema. Disponer un par de segmentos en un arreglo geométrico de tal manera que: (i) las longitudes de ellos estén en la misma proporción que las densidades ópticas de los medios y (ii) el arreglo sugiera un protocolo para anticipar el curso que seguiría un rayo de luz que viene de una fuente puntual y atraviesa la superficie de interfase entre los dos medios. El investigador exploró doce ejemplares ajustados al esquema propuesto. 
Todos los intentos fallaron en la tarea de anticipar la información recogida en la tabla de Witelo (Paralipomena, pp.101-10-4; GW, pp.84-8).

Segunda familia de analogías. Kepler dejó de concentrarse en la diferencia de densidades ópticas entre los medios y quiso fijarse, más bien, en el lugar aparente de las imágenes de objetos cuando estos se contemplan desde el segundo medio. Dada cierta similitud que el autor notaba entre las imágenes producidas en un espejo esférico y las observadas en virtud de la refracción, llegó a pensar en la posibilidad de encontrar una superficie cónica que, funcionando como un espejo, pudiera sustituir la interfase entre dos medios con densidades ópticas diferentes y replicar el mismo patrón de formación de imágenes (Paralipomena, pp.110-123; GW, pp.93-104). En su orden, Kepler ensayó con hipérbolas, elipses y finalmente, parábolas. De nuevo, las expectativas teóricas no se ajustaron a la información empírica. A pesar del fracaso; una cierta articulación de las dos familias habría podido conducir a la Ley de Snell-Descartes. ${ }^{11}$

Tercera familia de analogías. Kepler concibió la posibilidad de analizar la causa de la refracción a partir de dos componentes. Para establecer el primer componente, el autor conjeturó que: «[s]i el medio mismo pudiera ser considerado de manera aislada, con respecto a su densidad, el ángulo de refracción debería ser proporcional al ángulo de incidencia» (Paralipomena, IV, p.124; GW, p.105). El autor esperaba que la refracción, de suyo, fuera provocada por la diferencia de densidades ópticas de los medios. Del seguimiento de los argumentos se infiere que Kepler estaba pensando en la desviación, a saber: $d=r-i$, más que en el ángulo de refracción. Tal componente se puede, entonces, sintetizar con la siguiente expresión: $d_{1}=k i, d_{1}$ representa el primer componente de la desviación, $i$ es el ángulo de incidencia y $k$ una constante de proporcionalidad que debe ser función exclusiva de la diferencia de densidades ópticas de los medios. Tal constante es vital en la deducción del teorema fundamental.

Como segundo componente, el filósofo propuso, además, una resistencia del nuevo medio, de suerte que esta fuese mayor cuanto mayor fuese el ángulo de incidencia (Paralipomena, IV, p.124; GW, p.105). Argumentos asociados con la metafísica de la luz llevaron al autor a sostener que la desviación adicional, si el segundo medio es de mayor densidad óptica que el primero, es función de la secante del ángulo de refracción. ${ }^{12}$ Así las cosas, el primer componente obedece a la diferencia natural de los medios y a la circunstancia accidental del grado de inclinación del rayo incidente; en tanto que el segundo obedece al aumento accidental de la resistencia que ofrece el segundo medio en virtud de la inclinación accidental del rayo incidente. Después de seguir con atención algunas variantes del argumento inicial y los cálculos que sugiere el autor (Paralipomena, pp.124-29; GW, pp.105-9), se puede sintetizar así la ley propuesta por Kepler: $i-r=k i \sec r .{ }^{13}$ Gerd Buchdahl (1972, pp.293-4), usando 
expansiones de Taylor, mostró que la expresión, con $k=\frac{k^{\prime}-1}{k^{\prime}}$, puede reescribirse en la forma:

$$
\operatorname{sen}(i)=k^{\prime} \operatorname{sen}(r)\left(1-\frac{\left(k^{\prime}-1\right)\left(k^{\prime}-2\right)}{6} \operatorname{sen}^{2}(r)+\ldots\right)
$$

La ley de Kepler se acerca a la de Snell-Descartes si descontamos las potencias superiores de $\operatorname{sen}(r)$, lo que se justifica cuando los ángulos de refracción son pequeños. Igualmente, si el ángulo de incidencia es muy pequeño, también se puede esperar que $i$ y $r$ varíen en forma directamente proporcional.

Los cálculos que muestran que la pretendida ley de Kepler acoge con alguna aproximación la información de Witelo son muy complejos. El autor invita a considerar como dada una pareja de datos confiables e invita al lector, a manera de problema, a calcular el ángulo de refracción para cualquier incidencia posterior. Kepler tomo $\left(80^{\circ}, 30^{\circ}\right)$ como pareja confiable de la tabla de Witelo (Tabla 1). Con esos datos se puede estimar la constante de proporcionalidad. Dada la constante y un ángulo de incidencia, no resulta fácil evaluar el ángulo de refracción esperado. El filósofo hizo una aproximación por iteraciones siguiendo el método de la regla-falsa (Regula-falsi). Asume, primero, que la contribución de la segunda componente es nula; reconoce, por ello, que el cálculo que obtiene para la refracción es equivocado; hace una nueva valoración considerando ahora que la contribución de la segunda componente se puede tener en cuenta a partir del ángulo de refracción establecido en el primer intento. El filósofo sabe que esta nueva valoración también es equivocada, pero arroja un valor más cercano al esperado. Así que realiza un nuevo cálculo con esta nueva estimación y sigue iterando el procedimiento hasta que los valores así calculados ya difieren muy poco (Paralipomena, V, pp.127-9; GW, pp.108-9). La tabla 2 muestra los resultados que obtuvo Kepler y los compara con la información de Witelo. Kepler agrega la estimación esperada para el caso en el que se considere un ángulo de incidencia de $90^{\circ}$.

La ley de Kepler no coincide con la que la tradición moderna posteriormente acogió. No obstante, los resultados esperados se acercan cuando los ángulos son pequeños. En particular, se puede esperar que, en esos casos, no hay mayor desviación al aceptar que $i$ y $r$ varían en proporción directa. Kepler también pudo estimar la refracción esperada cuando el ángulo de incidencia se acerca a un ángulo recto. Como vemos en la siguiente sección, este par de resultados desempañan un papel importante en la deducción del teorema fundamental. 


\begin{tabular}{ccccc}
$\mathbf{i}$ & $\mathbf{d}_{1}$ & $\mathbf{d}_{2}$ & $\mathbf{d}_{1}+\mathbf{d}_{2}$ & $\begin{array}{c}\text { Desviación } \\
\text { citada por } \\
\text { Witelo }\end{array}$ \\
\hline $10^{\circ}$ & $2^{\circ} 25^{\prime}$ & $0^{\circ} 1^{\prime}$ & $2^{\circ} 26^{\prime}$ & $2^{\circ} 15^{\prime}$ \\
$20^{\circ}$ & $4^{\circ} 49^{\prime}$ & $0^{\circ} 10^{\prime}$ & $4^{\circ} 59^{\prime}$ & $4^{\circ} 30^{\prime}$ \\
$30^{\circ}$ & $7^{\circ} 14^{\prime}$ & $0^{\circ} 35^{\prime}$ & $7^{\circ} 49^{\prime}$ & $7^{\circ} 30^{\prime}$ \\
$40^{\circ}$ & $9^{\circ} 39$ & $1^{\circ} 23^{\prime}$ & $11^{\circ} 2^{\prime}$ & $11^{\circ}$ \\
$50^{\circ}$ & $12^{\circ} 4^{\prime}$ & $2^{\circ} 42^{\prime}$ & $14^{\circ} 46^{\prime}$ & $15^{\circ}$ \\
$60^{\circ}$ & $14^{\circ} 28^{\prime}$ & $4^{\circ} 40^{\prime}$ & $19^{\circ} 8^{\prime}$ & $19^{\circ} 30^{\prime}$ \\
$70^{\circ}$ & $16^{\circ} 52^{\prime}$ & $7^{\circ} 19^{\prime}$ & $24^{\circ} 11^{\prime}$ & $24^{\circ} 30^{\prime}$ \\
$80^{\circ}$ & $19^{\circ} 17^{\prime}$ & $10^{\circ} 43^{\prime}$ & $30^{\circ}$ & $30^{\circ}$ \\
$90^{\circ}$ & $21^{\circ} 43^{\prime}$ & $14^{\circ} 47^{\prime}$ & $36^{\circ} 30^{\prime}$ & \\
\hline
\end{tabular}

Tabla 2. Anticipaciones keplerianas

Fuente: los datos se han adaptado a partir de Paralipomena, V, p.128; GW, p.109

\section{El teorema fundamental de la óptica}

Antes de ocuparse del aspecto puramente geométrico, Kepler acopió la información central relativa a la anatomía ocular. Al respecto siguió muy de cerca la descripción que ofreció Felix Platter (1536-1614) en el tratado de 1583 De partis corporis humani structura et usu. Platter insinuó que es la retina la que tiene facultades de discernimiento (Paralipomena, V, p.178; $G W$ p.150) y advirtió que no hay contacto entre el cristalino y la retina. ${ }^{14}$

La tarea de ofrecer una demostración matemática del teorema fundamental demanda un recorrido extenso por otros teoremas y varios lemas auxiliares. Seguiremos este recorrido atendiendo los aspectos centrales. Tal y como ocurrió con las leyes del sistema planetario, la tradición acogió los resultados del trabajo del hombre de ciencia (en este caso el teorema fundamental) e ignoró los ricos y profundos procedimientos que llevaron a ellos.

Este fragmento del programa de investigación de Kepler se puede resumir en cuatro fases. En la primera, el autor estudia el proceso de formación y contemplación de imágenes cuando se interpone una esfera de cristal entre el objeto y el observador. En la segunda, introduce una distinción fina entre imagen y pintura. En la tercera, se establece una analogía entre el funcionamiento del ojo y el caso de la esfera. En la cuarta fase se demuestra el teorema.

Fase 1: formación de imágenes a través de una esfera cristalina. Imaginemos un objeto o fuente de luz $A$ al frente de una esfera cristalina de centro I (Figura 2). Se pide 
encontrar el lugar asignado a la imagen cuando el objeto es visto por dos ojos $B$ y $C$, ubicados simétricamente respecto a $A I$ detrás de la esfera de cristal (Paralipomena, V, p.192; GW, pp.162-163).

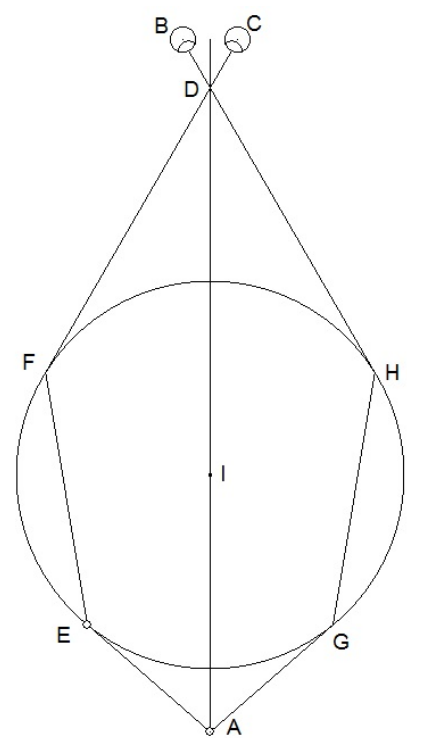

Figura 2: Objeto visto a través de una esfera cristalina [https://www.geogebra.org/m/ ujz5q6tv Objetos dinámicos: $A, E$ y el índice de refracción]

Imaginamos que los recorridos $A E F C$ y $A G H B$ corresponden a los trayectos de los rayos que, partiendo del objeto, llegan a cada ojo. No tenemos por qué suponer por ahora que todos los rayos que emergen de $A$ se congregan en $D$. De hecho, si el ángulo de incidencia no es pequeño, ese no será el caso. Dadas las condiciones de simetría, $F C$ y $H B$ se encuentran en un punto, $D$, sobre $A I$. De acuerdo con el criterio establecido por Kepler para la ubicación de imágenes, ${ }^{15}$ el observador asume que $D$ define la ubicación de la imagen contemplada. ${ }^{16}$ Cuando la iluminación de la esfera es muy tenue, puede ocurrir que observemos la imagen en $D$ como si estuviese flotando en el vacío. Kepler disfrutó, en el teatro de los artificios en Dresden, trucos impactantes que se apoyaban en esta idea. ${ }^{17}$

Fase 2: distinción entre imagen y pintura. Aun cuando, dadas las circunstancias psicológicas que devienen de la iluminación dominante sobre la esfera cristalina, nos sintamos inclinados a percibir la imagen $D$ contra las paredes de la esfera en el sector $F H$ (Figura 2), podemos recoger sobre una hoja de papel, que funciona como pantalla, una pintura de $A$ en el punto $D$. En ese orden de ideas, se puede decir que existe realmente una copia de $A$ en $D$ aunque por razones de circunstancias ambientales 
nos sintamos inclinados a divisar la imagen en el sector $F H$. Esto conduce a Kepler a ofrecer una interesante definición: «Dado que hasta el momento una imagen [Imago] ha sido un ser de razón [Ens rationale], ahora permitamos que las figuras que realmente existen de objetos sobre un papel o sobre otra superficie sean llamadas pinturas [picturae]» (Paralipomena, V, p.210; GW, p. 174). La concentración de luz que se recoge en $D$ por medio de una pantalla física es lo que Kepler denomina una pintura. La contemplación que adelanta el sensorio valiéndose de los dos ojos $B$ y $C$ para advertir la ubicación de la fuente de luz en $D$ se vale de la facultad de la imaginación y por eso merece el nombre de imagen. ${ }^{18}$ Como lo advierte Raz Chen-Morris: «La naturaleza limitada de los sentidos humanos fuerza a la mente humana a crear e inventar las construcciones matemáticas que producen una realidad visual inteligible» (2009, p.161). La importancia capital de la actividad psíquica en la formación de imágenes marca una diferencia central entre Kepler y los perspectivistas.

Judith Field sigue a Lindberg en su empresa de distanciar a Kepler del mecanicismo que le indilga Crombie. En ese sentido, con Lindberg, ella cree que Kepler sigue las técnicas que heredó de los perspectivistas. Aún así, ella sostiene que la filiación con los perspectivistas, que hace Lindberg de Kepler, es insuficiente para explicar por qué este último logró resultados completamente diferentes. Field conjetura que es el compromiso con el realismo lo que marca la diferencia (1986). A mi juicio, lo que hace de Kepler un pensador más cercano a la óptica moderna es su apego a las analogías guiadas por el razonamiento matemático y la importancia dada a la distinción entre pintura e imagen. Adicionalmente, si hay buenas razones para acoger el teorema fundamental, ya no habría necesidad de restringir la atención del sensorio sobre los rayos que inciden perpendicularmente al sistema tal como lo defendían los perspectivistas.

Fase 3: analogía entre el ojo y la esfera de cristal. Imaginemos ahora que la Figura 2 representa un objeto o fuente de luz $A$, la esfera de centro $I$ modela el globo ocular: $E G$ representa el sector de la pupila afectado y $F H$ la parte posterior del cristalino. Una pintura de $A$ debe darse efectivamente en $D$. Kepler defendió que la retina funge como una pantalla que permite recoger las pinturas que los objetos externos provocan en nuestro aparato perceptual. La Figura 3 (tomada de la Dióptrica) muestra la idea matriz que persigue Kepler: desde cada uno de los puntos $F B D$ de un objeto emanan haces de luz que encaran una lente $G H$; después de las dos refracciones esperadas se forma una pintura invertida del objeto en $C A E$; esta pintura puede recogerse en una pantalla.

Fase 4: demostración del teorema fundamental de la óptica. El complejo mecanismo de explicación propuesto por Kepler exige la conciliación de varios elementos que se pueden sintetizar así: (a) cada punto de la cara visible de un objeto puede concebirse como el vértice de un cono de radiación cuya base ocupa las dimensiones de la 


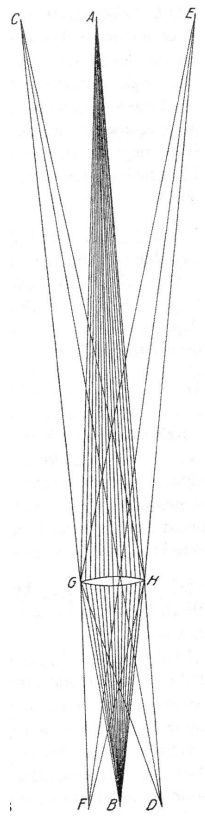

Figura 3: Formación de pinturas detrás de una lente; J. Kepler, (2008 [1611], p.463, Fig. 11)

pupila; (b) los rayos que provienen de cada uno de tales vértices e inciden en la base mencionada sufren, cada uno de ellos, varias refracciones y, a pesar de la diferencia de trayectos, convergen nuevamente en un punto que se encuentra precisamente en la retina; (c) en la retina se forma una especie de pintura que reúne los puntos de convergencia [concursus punctum], cada uno de ellos asociado con uno y solo un punto de la cara visible del objeto; (d) esta imagen pictórica invierte izquierda-derecha y arriba-abajo. Este mecanismo demanda una demostración geométrica cuidadosa de la conjetura central, a saber, todos los rayos que emanan de un punto frente a un observador convergen nuevamente en un punto después de las refracciones que sufren a través de los medios transparente que constituyen el ojo. Esta demostración exige, a su vez, probar varios teoremas y lemas previos. Así las cosas, no hay justicia en la siguiente evaluación de Shapiro: «La investigación geométrica de la refracción de Kepler fue en extenso cualitativa, descriptiva y aproximada» (2007, p.83). Es verdad que Kepler tenía en sus manos sólo una ley aproximada de la refracción, también es cierto que en algunos pasajes Kepler se declaró vencido en la tarea de hallar una ley precisa para ubicar los puntos de convergencia, pero es claro que toda su investigación estaba animada por un espíritu de precisión geométrica. Enumeraré los teoremas o problemas en la jerarquía que define la argumentación central, entre paréntesis indico la fuente en la exposición de Kepler. 
Problema 1 (Paralipomena, V, proposiciones 13, 15 y 16). Sea una esfera transparente de centro $A$, con una densidad óptica mayor que la del medio que la envuelve, y una recta $A F$ que pasa por el centro y funge como el eje de la esfera (Figura 4). El problema pide hallar los puntos sobre el eje $A F$ tales que los rayos que provienen de cada uno de ellos (a) no intersecan el eje al otro lado de la esfera; y, por otro lado, hallar los que (b) sí lo hacen.

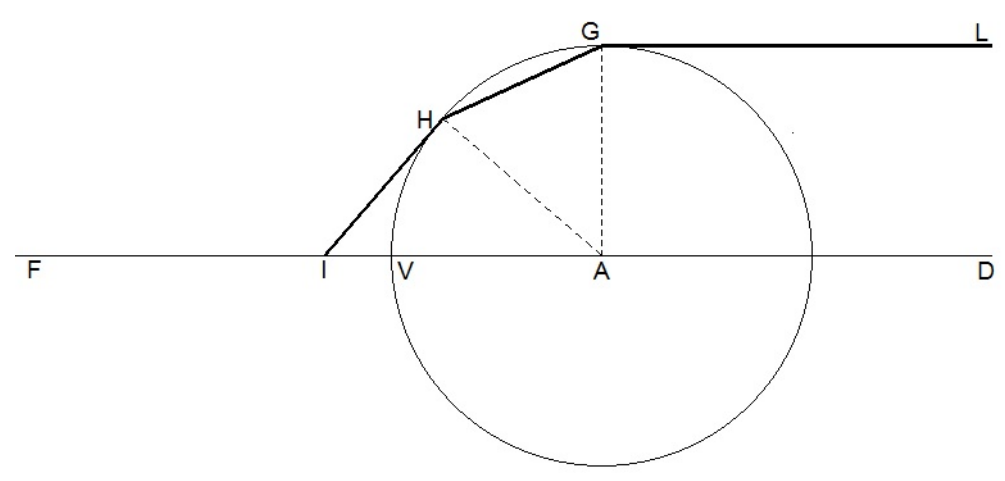

Figura 4: Teorema 1 [https://www.geogebra.org/m/bu6t6zcn. Se puede cambiar el índice de refracción)

La demostración hace uso del siguiente lema.

Lema 1: Consideremos un rayo que incide sobre una esfera transparente en el punto $B$ formando un ángulo de incidencia $i_{1}$ (Figura 5). Este se refracta en la dirección $B C$ formando con la normal un ángulo $r_{1}$. Cuando este rayo encara la segunda refracción en el punto $C$, lo hace formando ahora un ángulo de incidencia $i_{2}$. Es claro que $r_{1} \cong i_{2}$. Si admitimos que la ley de la refracción, cualquiera que sea, es reversible, se tiene: $i_{1} \cong r_{2} \cdot{ }^{19}$

Volvamos ahora al problema 1 . Sea $F A D$ la recta que funge como eje de la esfera de centro $A$ (Figura 4). Trazamos $G L$ paralelo a $A D$, con $G A D$ recto. Dado que la esfera es más densa ópticamente que el medio circundante, cuando un rayo incide formando un ángulo recto (en este caso $L G$ ), el rayo se refracta con el máximo ángulo de refracción posible. Este ángulo depende exclusivamente de la diferencia de densidades ópticas y se puede calcular con una ley adecuada para la refracción. Kepler, con su ley, calculó este ángulo para el paso de aire al agua y obtuvo como desviación $36^{\circ} 30^{\prime}$ (ver tabla 2), lo que conduce a un ángulo de refracción de $53^{\circ} 30^{\prime} .{ }^{20}$ Esta es una aproximación que deviene de las analogías empleadas para derivar la ley de la refracción.

Trazamos el segmento $G H$ de tal manera que el ángulo $A G H$ coincida con el ángulo límite de refracción. Después trazamos la perpendicular $H I$ al segmento HA. I es el punto de corte de esta perpendicular con el eje $A F$. Dada la reversibilidad de la 


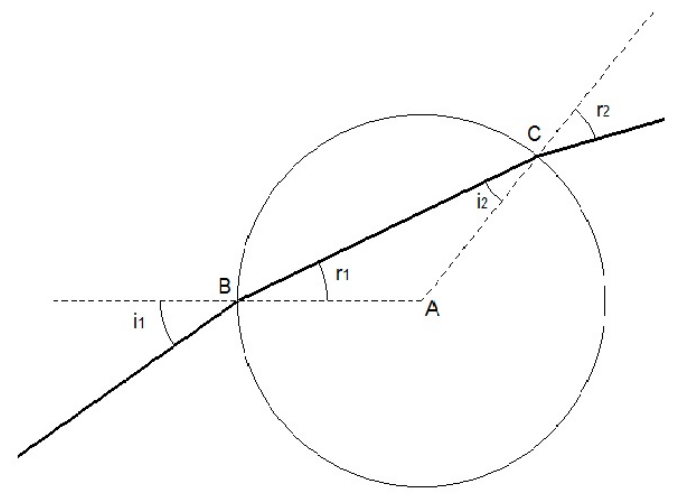

Figura 5: Lema 1 [https://www.geogebra.org/m/htw2zqfn. Se puede cambiar el ángulo de incidencia y el índice de refracción]

refracción, probaremos ahora que cada uno de los puntos en el segmento $I V$ ( $V$ es el corte de la esfera con el eje $A D$ ) satisface la exigencia (a) planteada en el problema.

Tomemos un punto $O$ que se encuentre en una posición intermedia sobre el segmento $I V$. $C$ es el punto de incidencia de algún rayo que viene desde $O$. El mayor ángulo de incidencia ocurre cuando $O C$ es tangente a la circunferencia (Figura 6). En este caso, $\angle O C E \cong \angle I H G$ ( $E$ es el punto de incidencia en la nueva interfase esfera-aire). Como $C$ es un punto necesariamente por debajo de $H$, Kepler espera que $C E$ y $H G$ se crucen en algún punto del segmento $H G$. Este resultado deviene de la contemplación del diagrama que hace posible la libertad de movimiento de $C$ que se restringe entre un punto cercano a $V$ y el momento en el que $O C$ sea tangente a la circunferencia. Si el lector se auxilia con la modelación, puede seguir las acciones cinéticas que acompañan el razonamiento de Kepler. EM muestra la segunda refracción esperada; del lema 1 se infiere $\angle O C E \cong \angle C E M$. Es de esperar que la prolongación de $M E$ interseque a $A D$ por delante de la esfera (en $K$ sobre la semirrecta $O I)$. Si $C$ se desplaza hacia $V$, conservando $O$ fijo, se esperan ángulos de refracción menores, lo que provoca un acercamiento de $K$ hacia $I$. El acompañamiento con la modelación deja ver este punto con claridad.

La Figura 7 muestra un punto $O$ más alejado de la esfera que $I$. $C$ es el punto de máxima incidencia, $C E$ la máxima refracción y $E M$ la segunda refracción. Como en este caso $C$ es un punto más alto que $H, E$ está a la derecha de GA. Dado que $E M$ es tangente a la circunferencia en $E$ (por el lema 1), esta recta corta a $A D$ al lado de la esfera opuesto al lado donde se encuentra $O$.

La Figura 8 exhibe el mismo punto $O$ y un cierto punto de incidencia $C$ (cercano a $V$ ) para el cual la prolongación de la segunda refracción $E M$ encuentra al eje del mismo lado en donde se encuentra $O{ }^{21}$ Así entonces, los puntos más alejados que $I$ 


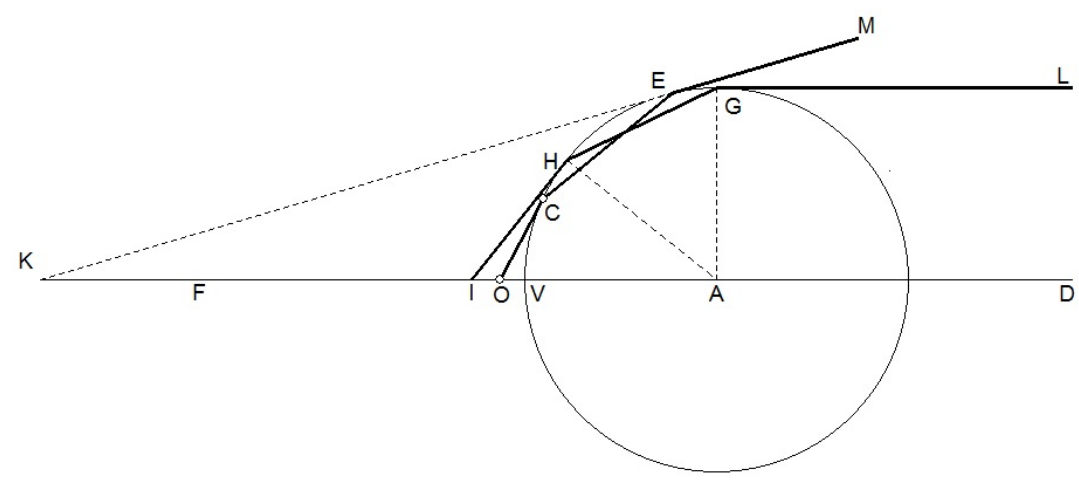

Figura 6: Puntos radiantes en el segmento $I V$ [https://www.geogebra.org/m/bu6t6zcn. Seleccione "Punto O" para tener acceso al punto movible $O$ y restrinja su movimiento al segmento $I V$. Objetos dinámicos: $O, C$ y el índice de refracción]

pueden considerarse como fuentes radiantes para las cuales algunos rayos intersecan al eje al otro lado de la esfera y otros lo hacen de tal manera que su prolongación corta al eje al mismo lado. Si el lector sigue la modelación, puede variar la elección de $C$ y notar que para una franja $K$ se encuentra a la izquierda y para otra lo hace a la derecha.

Kepler conjetura la existencia de un punto límite $F$ sobre el eje $A D$ tal que, más allá de $F$ toda la radiación que proviene de un punto allí ubicado interseca al eje al otro lado de la esfera después de la segunda refracción. Entre $F$ e $I$, los puntos radiantes se comportan de tal manera que algunos de sus rayos intersecan al eje $A D$ al otro lado de la esfera, mientras que otros rayos no lo hacen. Los puntos radiantes entre $I$ y $V$ no tienen rayos que se intersequen con $A D$ al otro lado de la esfera. Kepler, sin embargo, no halló un algoritmo para encontrar $F$, como sí lo hizo con $I$. Para el caso, el autor se limita a invocar el auxilio del lector: «Yo he perdido la esperanza de definir geométricamente el punto exacto en el cual la última intersección ocurre; yo le ruego, lector, me ayude en este punto» (Paralipomena, V, p.205; GW, p.172). Así entonces, el argumento de Kepler asegura la existencia del punto $F$, pero no logra ofrecer el protocolo para encontrarlo. El autor sostiene que la existencia del punto está garantizada si los ángulos de incidencia son muy pequeños. Si el lector sigue las modelaciones ingresando a los enlaces, puede desplazar los puntos sugeridos y acompañar los que imaginamos pueden ser los razonamientos cinéticos que acompañan el empleo de los diagramas.

Si suponemos que un objeto sobre el eje del ojo se percibe con cierta claridad cuando la segunda refracción interseca al eje del otro lado y suponemos que el cristalino tiene estructura esférica y que las densidades ópticas del aire, el humor acuoso 


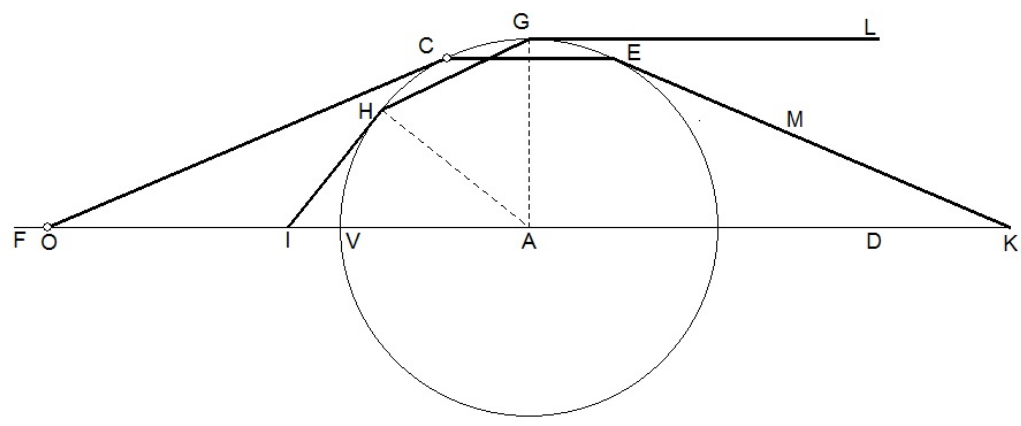

Figura 7: Puntos radiantes más alejados de $I$ [https://www.geogebra.org/m/bu6t6zcn Asegúrese de que $O$ se encuentre más alejado que $I]$

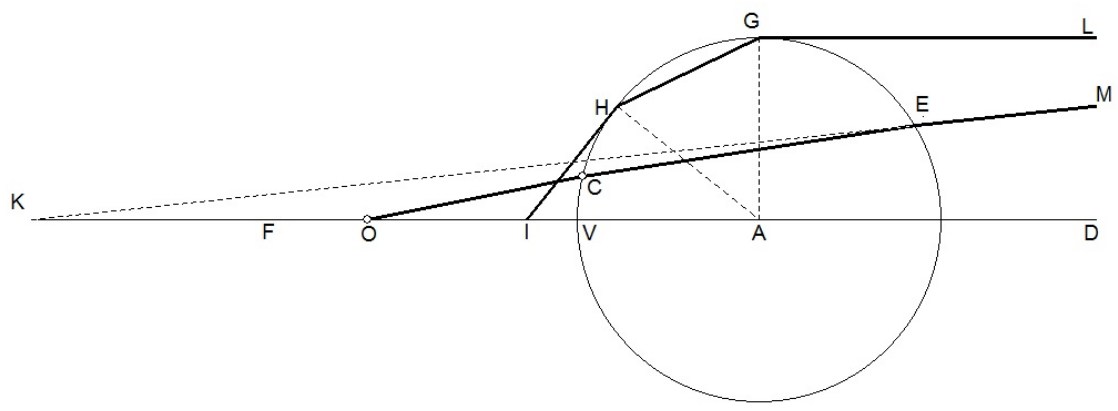

Figura 8: Figura 8. Puntos radiantes más alejados de $I$, rayos que intersecan al eje del mismo lado de la esfera [https://www.geogebra.org/m/bu6t6zcn Asegúrese de que $O$ se encuentre más alejado que $I$ y $C$ se acerque a $V]$

y el humor vítreo son idénticas entre sí, podemos esperar que (i) los objetos radiantes ubicados entre $I$ y $V$ no se pueden percibir con claridad, (ii) los objetos entre $I$ y $F$ pueden percibirse con alguna claridad, (iii) los objetos más allá de $F$ se pueden percibir con la máxima claridad posible. No obstante, falta agregar condiciones para la percepción clara. La integridad del método de Kepler no se puede poner en duda aunque no se establezca un protocolo preciso para hallar el punto $F$.

Lema 2 (Paralipomena V, Lema para la prop.9). Sea $E$ un punto exterior a una circunferencia de centro $F$ y $A G$ un diámetro cuya extensión contiene a $E$ (Figura 9). Si se trazan rectas desde $E$ por una secuencia de puntos igualmente distanciados y sobre la semicircunferencia, empezando con $A$, los ángulos formados entre ellas resultan desiguales, los que se encuentran más cerca al diámetro son mayores.

Tomemos los puntos $B, C$ y $D$ de tal manera que los ángulos $A F B, B F C$ y $C F D$ sean 


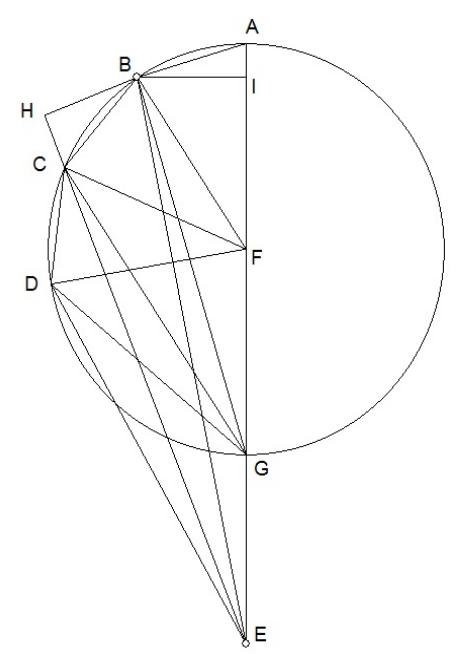

Figura 9: Lema 2 [https://www.geogebra.org/m/ztxczcdj Objetos dinámicos: $E$ y $B$ ]

congruentes. ${ }^{22} B I$ y $B H$ son perpendiculares a $A G$ y $C E$ respectivamente. Dado que los ángulos $G A B$ y $G C B$ son opuestos en el cuadrilátero inscrito $G A B C$, ellos suman dos rectos; por lo tanto, $G A B$ es suplemento de $G C B$. Como $E C B$ es mayor que $G C B$, su suplemento, $H C B$, es menor que el suplemento de $G C B$. Por tanto, $H C B$ es menor que $G A B$ (que es el mismo $E A B$ ). De lo anterior, más el hecho de que los triángulos $B H C$ y $B I A$ son rectángulos con hipotenusas congruentes, se deduce que $B I$ es mayor que $B H$. Como los triángulos rectángulos $E H B$ y $E I B$ coinciden en su hipotenusa $E B$, se deduce, de la desigualdad anterior, que el ángulo $A E B$ es mayor que el ángulo $B E H$ (que es el mismo $B E C$ ). El mismo esquema se puede repetir para los ángulos restantes.

Teorema 1 (Paralipomena, V, prop.9). Los rayos paralelos que inciden sobre una esfera de densidad óptica mayor que la del medio que la envuelve intersecan al eje en puntos diferentes. Los rayos más distantes del eje lo intersecan en puntos más cercanos a la esfera.

Sean $L A, M B, N C$ tres rayos paralelos que inciden en la esfera de centro $F$ justo en los puntos $A, B$ y $C$ ubicados de tal manera que el arco $A B$ es congruente con el arco $B C$ (Figura 10). Dadas las condiciones, el ángulo de incidencia NCC' es dos veces mayor que el ángulo de incidencia $M B B$ '. Asumamos que la esfera tiene una densidad óptica superior a la del medio que la envuelve. $M B$ en consecuencia, se refracta hacia la normal e interseca al eje en algún punto $E$. Debe ocurrir que $N C$ se refracte cortando al eje en un punto diferente a $E$. El argumento propuesto por Kepler sigue un razonamiento similar al siguiente. Nótese que el argumento se deriva 


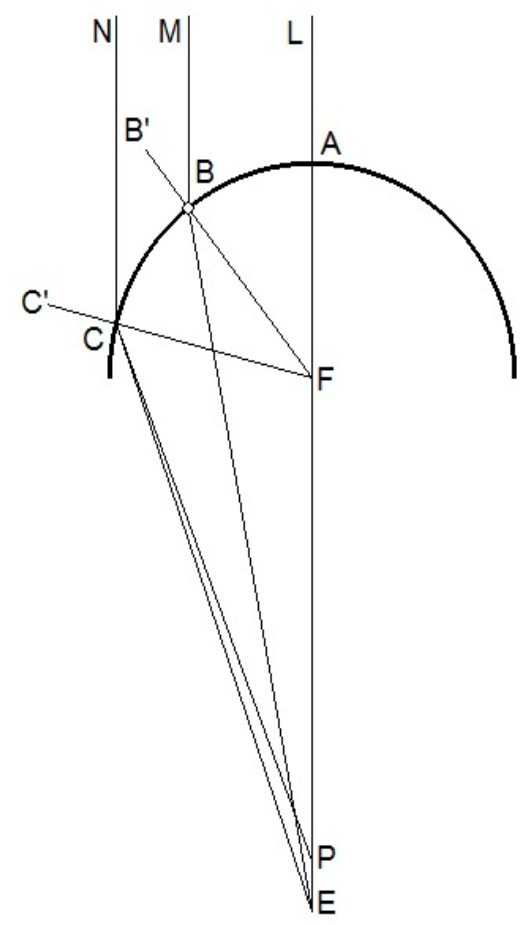

Figura 10: Teorema 1 [https://www.geogebra.org/m/f9vrgbj4. Seleccione "Primera refracción" para tener acceso al punto movible $B]$

de las premisas que Kepler emplea en su tercer tratamiento de la ley imprecisa para la refracción. Esta ley supone que la desviación $d$ es la reunión de dos componentes: $d_{1}$ que es directamente proporcional a $i$ y $d_{2}$ que depende de la secante de $r$. Consideremos, por ahora, los efectos del primer componente. Si asumimos que NC se refracta por la recta $C E$ incurrimos en contradicción con la mencionada ley. Veamos el caso. Dado que el ángulo de incidencia $N C C^{\prime}$ es dos veces mayor que el ángulo de incidencia $M B B^{\prime}$, la desviación $C E A$ debe ser dos veces mayor que la desviación $B E A ;{ }^{23}$ pero este no puede ser el caso si se supone que el rayo $N C$ se refracta pasando por $E$, pues $B E C$ difiere de $A E B$ (por el Lema 2). Si el rayo $N C$ se refracta atendiendo al primer componente que exige Kepler, este rayo interseca al eje en un punto $P$ de tal manera que el ángulo $A P C$ es el doble del ángulo $A E B$. Como corolario del Lema 2 , se infiere que este punto $P$ debe estar más cerca de la esfera que $E$. Si a esta desviación le agregamos el segundo componente, la diferencia entre $E$ y $P$ se hace mayor toda vez que $d_{2}$ se incrementa más con iguales incrementos de $i .{ }^{24}$ Si agregamos ahora la segunda refracción, cuando la luz regresa al primer medio, nada nos hace esperar una convergencia de las refracciones sin violar la proporcionalidad exigida por la ley 
de Kepler. La Figura 11 muestra el tipo de refracción esperada para NC si asumimos que $M B$ se refracta adecuadamente y nos restringimos al estudio de la desviación $d_{1}$. Las nuevas refracciones se dirigen ahora a $E^{\prime}$ y $P^{\prime}$. Si el lector accede a las modelaciones, puede ver con más fuerza las acciones cinéticas que complementan el uso de los diagramas.

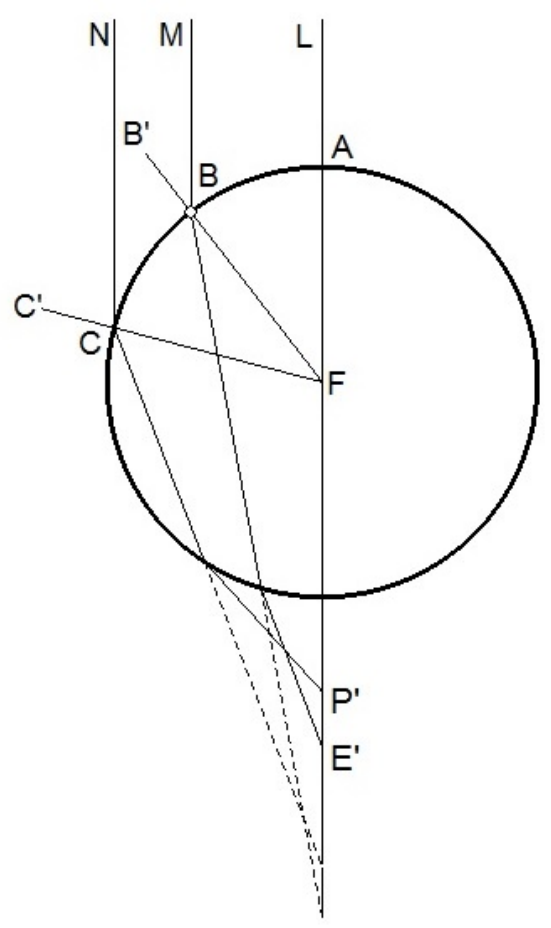

Figura 11: Doble refracción en el Teorema 1 [https://www.geogebra.org/m/f9vrgbj4 Seleccione "Segunda refracción" para tener acceso al punto movible $B$ ]

Del teorema 1 se deriva una consecuencia importante con miras a elucidar las refracciones que ocurren detrás del ojo. Asumamos que la estructura cristalina del ojo es esférica e imaginamos un objeto lo suficientemente alejado como para que todos sus rayos intersequen el eje por detrás de la esfera. Si ahora imaginamos que tal objeto está tan lejos que no hay error en pensar que sus rayos inciden en forma paralela al eje, nos vemos obligados a admitir que no todos los rayos convergen en el mismo punto sobre el eje. Si la visión clara y distinta exige tal convergencia, debemos imponer condiciones adicionales.

Teorema 2 (Paralipomena, V, prop. 24). Rayos que estaban dirigidos hacia un mismo punto y que no logran llegar allí en virtud de la refracción en la interfase hacia 
un medio de menor densidad óptica pueden reunirse en otro punto más cercano si se hacen modificaciones a la superficie de refracción.

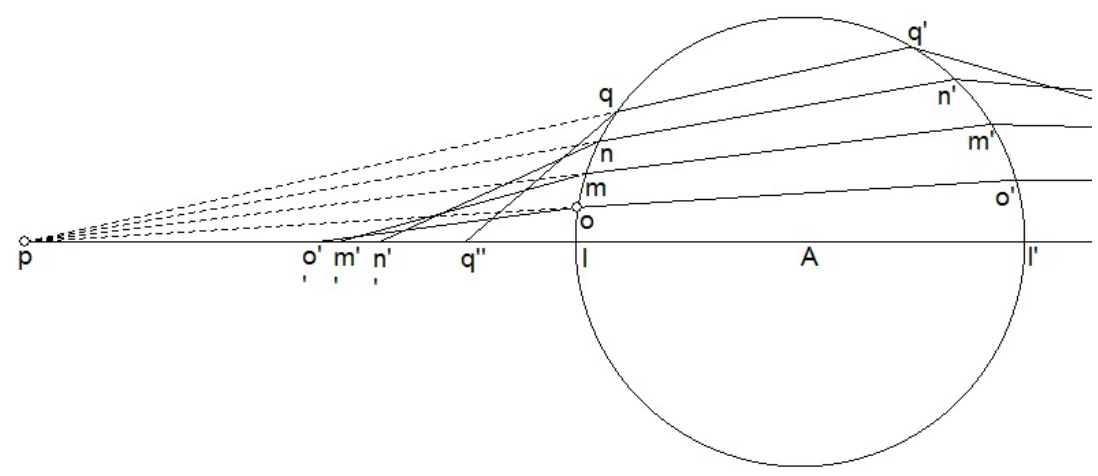

Figura 12: Teorema 2 [https://www.geogebra.org/m/we8e9ucu. Objetos dinámicos: p, o y el índice de refracción]

Sea $p$ el punto al que habrían llegado los rayos $q^{\prime} q, n^{\prime} n, m^{\prime} m, o^{\prime} o, l^{\prime} l$ de no ser por la refracción provocada en la interfase con un medio de menor densidad óptica (Figura 12). Del teorema 1, es claro que los rayos que incidieron en la parte opuesta del globo no podrían ser paralelos. Entre más alejado del eje Ap esté el rayo, mayor es el ángulo de incidencia y mayor será, de acuerdo a la ley de Kepler, el ángulo de refracción. Por esa razón, entre más alejado del eje llegue el rayo incidente, el rayo refractado cortará al eje en un punto más cercano al globo. Sean, entonces, $q q^{\prime \prime}, n n^{\prime \prime}$, $m m^{\prime \prime}, o o^{\prime \prime}$ las refracciones de $q^{\prime} q, n^{\prime} n, m^{\prime} m, o^{\prime} o$, respectivamente y $q^{\prime \prime}, n^{\prime \prime}, m^{\prime \prime}, o^{\prime \prime}$ las intersecciones con el eje. Aun cuando Kepler no cuenta con un algoritmo para hallar el punto $F$, más allá del cual la radiación completa de un punto radiante interseca al eje del otro lado después de dos refracciones, él sostiene que dicho punto debe hallarse muy cerca de las refracciones que se producen con ángulos de incidencia muy pequeños. En este caso, dicho punto debe acercarse a o" (Paralipomena, V, props. 14 y 15). La idea brillante de Kepler consiste en sugerir que si queremos que $q q^{\prime \prime}, n n^{\prime \prime}, m m^{\prime \prime}$ se acerquen, respectivamente, a $q o^{\prime \prime}, n o^{\prime \prime}, m o^{\prime \prime}$, debemos moldear la forma geométrica de la superficie de la interfase. Así las cosas, necesitamos que, por ejemplo, el trayecto $q^{\prime} q q^{\prime \prime}$ sea modificado por un trayecto cercano a $q^{\prime} q o^{\prime \prime}$; para ello se requiere disminuir la desviación que provoca la refracción. Si no podemos hacer modificaciones en las densidades ópticas, tenemos que disminuir el ángulo con el que $q^{\prime} q$ incide al nuevo medio. Esto se logra si cambiamos la curvatura de la superficie de separación en las vecindades de $q$. Lo propio hay que hacer en las vecindades de los puntos $n$ y $m$, salvo que las modificaciones se hacen cada vez menos drásticas. 
Kepler afirma, sin demostrarlo, que la nueva superficie se debe ajustar a una cónica, probablemente cercana a una hipérbola; aduce para ello que en el capítulo IV de los Paralipomena demostró la mayor efectividad de la hipérbola para representar las refracciones. ${ }^{25}$

Kepler espera que la multiplicidad esperada de trayectos $q q^{\prime \prime}, n n^{\prime \prime}, m m^{\prime \prime}, o o^{\prime \prime}$ se organicen en la envolvente hiperbólica similar a la que exhibe la figura 13 (Paralipomena, V, p.211; $G W$, p.175). ${ }^{26}$

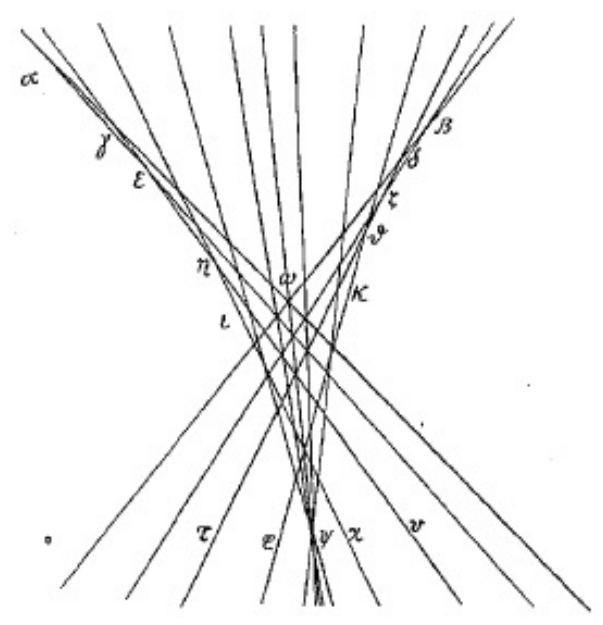

Figura 13: Envolvente hiperbólica

La figura 14 muestra un globo ocular con superficie anterior esférica y posterior elíptica. También muestra el trayecto $\mathrm{mm}^{\prime \prime}$ que tiene el rayo si la superficie posterior es esférica. Si dicha superficie se moldea de tal manera que adquiera la forma elíptica que muestra la figura, el trayecto se acerca a la intersección con el eje en el punto $p$; dicha intersección es ahora $m e^{\prime \prime}$. El lector puede adelantar variaciones cinéticas a las elipses, en las modelaciones de GeoGebra, para contemplar con más fuerza el argumento de Kepler.

Kepler, con espíritu teleológico, concluye:

En consecuencia, es evidente el plan de la naturaleza concerniente a la superficie posterior del humor cristalino en el ojo. Esto es, ella deseaba reunir todas las radiaciones provenientes de un objeto visible en un punto singular de la retina después de entrar por la apertura de la úvea [pupila], con el ánimo de que el punto de la pintura pueda ser del todo evidente, y que el resto de los puntos de la pintura no sean confundidos por rayos extraños. (Paralipomena, V, p.214; GW, p.179)

Si la retina se encuentra antes o después de la convergencia, la percepción pierde claridad y distinción. Así las cosas, el plan de la naturaleza consistía en garantizar 


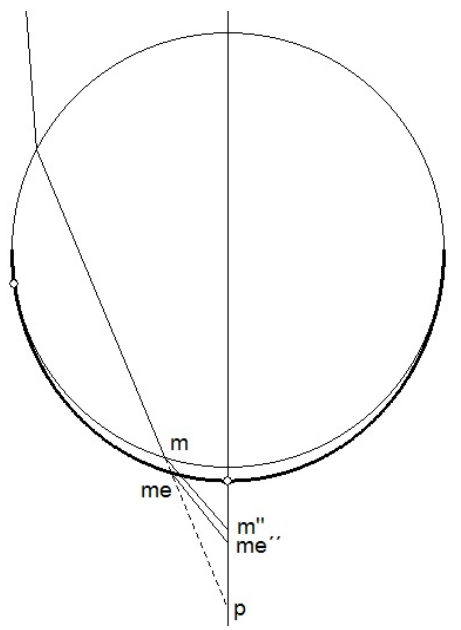

Figura 14: Cristalino con superficie posterior elíptica [https://www.geogebra.org/m/ wpeev8vp Objetos dinámicos: $p$, el punto de incidencia inicial, el índice de refracción y los puntos azules sobre la elipse]

las condiciones para una percepción clara y distinta. Dadas las limitaciones que la forma esférica impone a la convergencia, limitaciones que han salido a la luz en los anteriores teoremas, la naturaleza debe propiciar modificaciones a la esfericidad con el ánimo de salvar la convergencia.

Teorema 3 (Paralipomena V, prop. 23). Sea HI un objeto ubicado perpendicularmente al eje $H A$ de una esfera de centro $A$ y densidad óptica mayor que la del medio que la envuelve (Figura 15). Sea $K$ el punto a partir del cual se empieza a recoger todas las radiaciones que vienen de $H$ (Problema 1) y $B E$ las dimensiones de una pequeña rendija que sólo permite el paso de algunos rayos que vienen de $I$. Kepler demuestra que las formas radiantes del objeto $H I$ pueden provocar la formación de una pintura detrás del globo, pintura que se puede recoger invertida sobre un papel. En el marco de la estrategia analógica de Kepler, se espera que la abertura EB simule la pupila y la esfera la estructura completa del lente cristalino.

La figura muestra en líneas punteadas el diámetro extendido que contiene a $I$; también muestra el trayecto de tres rayos que provienen de $I$ y pasan por la rendija; estos rayos intersecan el eje en los puntos $N, L$ y $M$. La pintura de $I$ es más clara en las vecindades de $L$, mientras la pintura provocada por $H$ lo es en las vecindades de $K$. Si $I$ está a la izquierda de $H, L$ estará a la derecha de $K$. Entre más pequeña sea la rendija, menor es la dispersión de los trayectos de luz y, en consecuencia, más nítida es la imagen pictórica (Figura 15b). Si la magnitud del ángulo EIB no es muy grande y la abertura $E B$ es, comparada con el radio de la esfera, muy reducida en 

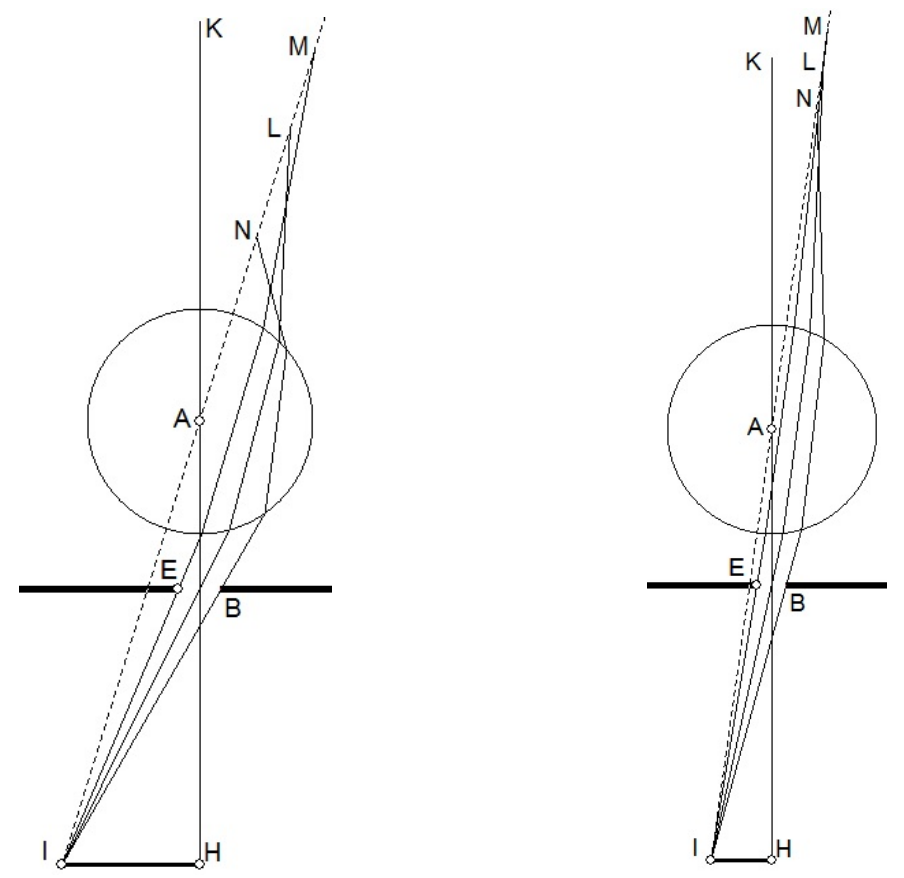

Figura 15: Teorema fundamental de la óptica [https://www.geogebra.org/m/fkksdsfq Seleccione " $R_{1}$ ", " $R_{2}$ " o " $R_{3}$ " para hacer seguimiento a los rayos individuales. Objetos dinámicos: $A, E, I, H$, índice de refracción y diámetro de la circunferencia]

sus dimensiones, los puntos $N, L$ y $M$ convergen en forma más fina (Figura 15b). La manipulación cinética que permite la modelación en GeoGebra deja ver con más fuerza la riqueza del argumento kepleriano. Esto explica por qué es deseable unas dimensiones reducidas para la pupila y por qué hay más claridad en la percepción cuando la amplitud angular de los rayos que abrazan al objeto es pequeña. En estas condiciones se puede decir, al tenor del teorema fundamental de la óptica, que un haz de rayos homocéntricos de un lado de una esfera cristalina se reúne en un haz homocéntrico del otro lado de la esfera después de las dos refracciones, siempre que la amplitud del haz sea reducida en comparación con las dimensiones del diámetro de la esfera y se acepten sin dificultad las aproximaciones llevadas a cabo.

La heurística kepleriana que condujo al teorema fundamental, además de compleja, es peculiar por los giros en la argumentación. Los teoremas geométricos no imponen de suyo la convergencia de rayos refractados que provienen de una misma fuente puntual. Muy al contrario, tales teoremas exhiben todas las obstrucciones que, de hecho, impiden la convergencia que se quiere defender. Así las cosas, los teoremas dejan ver cuáles son las condiciones adicionales que hay que exigir para aproximarse 
a una convergencia conveniente. En ese orden de ideas, si se quiere que un haz homocéntrico se reúna de nuevo después de enfrentar un par de refracciones, se requiere que el haz tenga una amplitud angular muy pequeña y que la superficie de interfase en la segunda refracción se pueda modificar para optimizar la convergencia.

\section{Demostraciones posteriores}

Aun cuando la ley de la refracción de Kepler no anticipaba con claridad la información empírica disponible, fue posible defender el teorema fundamental dado que el cálculo exigía tener en cuenta ángulos de incidencia muy pequeños. Después de admitir la ley de Snell-Descartes, fue posible que, así como Newton aportara una demostración de las leyes celestes de Kepler en el marco de la mecánica moderna, se pudiera revisar la conjetura de Kepler a partir de un nuevo fundamento. Nicolas Malebranche (16381715), apoyado en dicha ley, propuso una brillante demostración de la conjetura. En una breve adenda al final de la Investigación de la verdad, el filósofo anticipó el punto de concurrencia de los rayos que proviniendo de un objeto puntual luminoso sufren dos refracciones al atravesar una lente biconvexa (2009 [1712], pp.929-35). Presento los esbozos de su demostración.

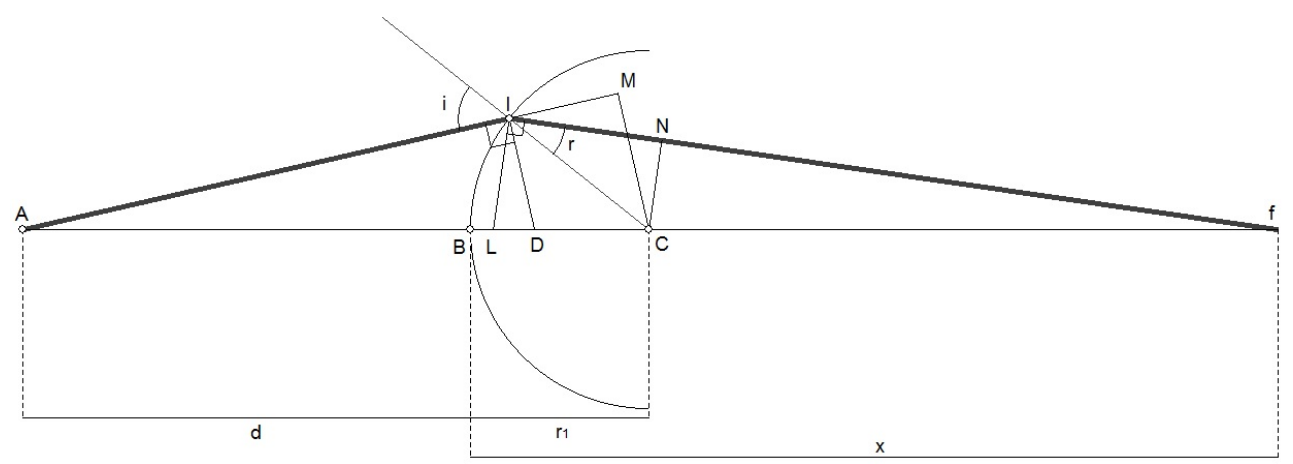

Figura 16: Paso por la primera interfase de una lente biconvexa [https://www.geogebra.org/ m/ap2nrj32. Seleccione "Primera refracción" para estudiar el tránsito por la primera interfase. Objetos dinámicos: $A, B, C_{1}, I$ e índice de refracción]

Supongamos que $A$ es la fuente puntual de luz ubicada frente a una de las caras convexas de la lente, $A I$ es un rayo incidente, que después supondremos muy cerca del eje, e If el correspondiente rayo refractado (Figura 16). De acuerdo a la Ley de Snell-Descartes, esperamos que $\frac{\operatorname{sen}(i)}{\operatorname{sen}(r)}=n_{21}$, con $n_{21}$ un valor constante que solo depende de las propiedades ópticas de los medios.

Si se exige que el ángulo de incidencia sea pequeño, $I$ debe acercarse demasiado 
a $B . C_{1}$ es el centro de la esfera. Dada esta aproximación y el hecho de que las parejas de triángulos $A I D, A M C_{1}$ y $I L F, N C_{1} f$ son semejantes, Malebranche muestra que la distancia $B f$ se puede calcular así:

$$
x=\frac{n_{21} d r_{1}}{d\left(n_{21}-1\right)-r_{1}} .
$$

Consideremos lo que pasa ahora en la segunda refracción (figura 17). Sea $H$ el nuevo punto de incidencia en la segunda cara de la lente biconvexa. $C_{2}$ es el centro de la esfera que delimita la segunda cara de la lente. Ahora esperamos que $\frac{\operatorname{sen}(i)}{\sin (r)}=n_{32}$ con $n_{3} 2$ el índice de refracción del tercer medio con respecto al segundo.

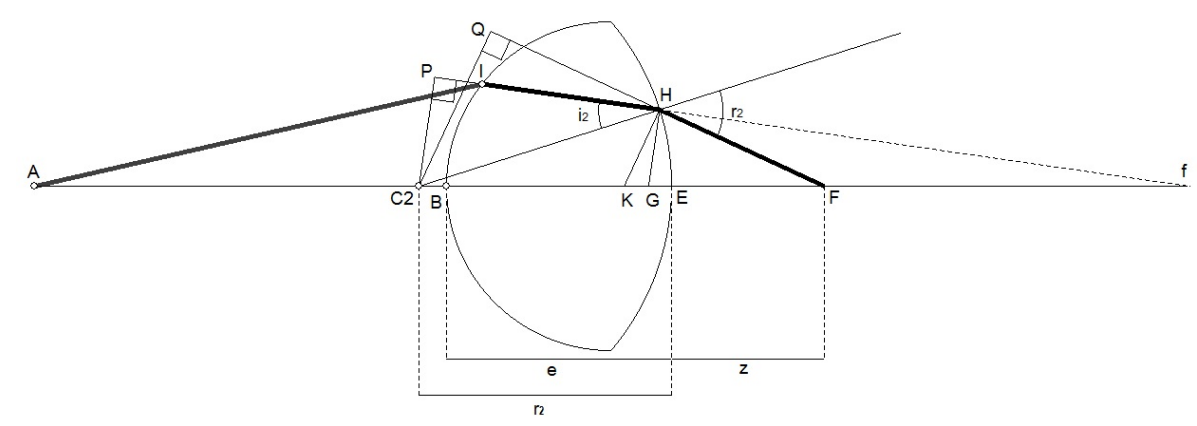

Figura 17: Paso por la segunda interfase de una lente biconvexa [https://www.geogebra.org/ m/ap2nrj32. Seleccione "Segunda refracción" y desactive "Primera refracción" para estudiar el tránsito por la segunda interfase. Objetos dinámicos: $A, B, I$ e índice de refracción]

Si se exige que $i_{1}$ sea pequeño, $H$ debe acercarse demasiado a $E$. Dada esta aproximación y el hecho de que las parejas de triángulos $C_{2} P f$, GHf y KHF, $C_{2} Q F$ son semejantes, Malebranche muestra que la distancia $E F$ se puede calcular así:

$$
z=\frac{n_{32}(x-e) r_{2}}{(x-e)\left(1-n_{32}\right)+r_{2}} .
$$

Cuando el ángulo de incidencia es muy pequeño, la ubicación de los puntos $f$ y $F$ depende sólo de la geometría de la lente, de las propiedades ópticas de los medios que intervienen y de la ubicación de la fuente $A$. Así las cosas, si conocemos $d, r_{1}$, $r_{2}, n_{21}, n_{32}$, y $e$, podemos determinar la distancia precisa, $z$ a la que convergen los rayos que provienen de $A$, siempre que no se alejen mucho entre sí. Ahora bien, si de un objeto ubicado en $A$ fijamos el lugar en donde queremos que se recoja la pintura en una posición definida como la retina, podemos calcular o bien el espesor $e$, o bien el radio de la esfera, $r_{32}$, que satisfacen la condición impuesta. Malebranche 
hizo un cálculo para un par de valores particulares de $n_{21}$ y $n_{32}$, a saber $3 / 2$ y $2 / 3$. Malebranche asumió que el índice de refracción cuando la luz pasa del aire al humor cristalino es $3 / 2$ (2009 [1712], p.902). ${ }^{27}$

En el siglo XIX, Hermann von Helmholtz demostró un poderoso resultado del cual se desprende la validez del teorema de Kepler. Este remite a un sistema óptico centrado $^{28}$ en el que los rayos ingresan a los nuevos medios con ángulos de incidencia pequeños. Helmholtz demostró que si conocemos la ubicación de seis puntos -llamados puntos cardinales del sistema: dos puntos focales, dos principales y dos nodales- es posible, de una manera simple y sin importar la complejidad del sistema, encontrar la posición y el tamaño de la imagen producida por un objeto (2005 [1909], vol. 1, p.61). ${ }^{29}$ Los dos puntos nodales son puntos conjugados que satisfacen la siguiente condición: si un rayo incide en el sistema después de pasar por el primer punto nodal $\left(N_{1}\right)$, o si su prolongación pasa por dicho punto, emerge finalmente del sistema en la misma dirección y pasa por el segundo punto nodal $\left(N_{2}\right)$. A partir de la información anatómica del sistema ocular se puede advertir que los dos puntos nodales, así como los dos puntos principales, se encuentran muy cerca uno del otro. En ese orden de ideas, no se incurre en mayor error si se admite que los dos puntos nodales se funden en un solo punto ubicado a unos $0,56 \mathrm{~mm}$ al frente de la cara posterior del cristalino (vol 1. p.95). Así las cosas, aunque el sistema ocular esté formado por varias esferas que difieren en sus índices de refracción, este se puede sustituir por una única esfera, conocida como el "ojo reducido de Listing" (vol. 1, p.96), cuyo centro se identifica con el punto medio de los dos puntos nodales. La figura 18 ilustra la reducción. El sistema óptico centrado es sustituido por la esfera de centro $N_{1-2}$ que pasa por $P_{1-2}$; en la figura aparece en trazos discontinuos. ${ }^{30}$ Para ubicar el punto de activación retiniana provocada por un objeto $A$, basta trazar la recta que une el punto con $N_{1-2}$ y conseguir el corte con la retina $A^{\prime}$. Así las cosas, el ojo reducido de Listing ha de sustituir la esfera que Kepler imagina en la figura 18.

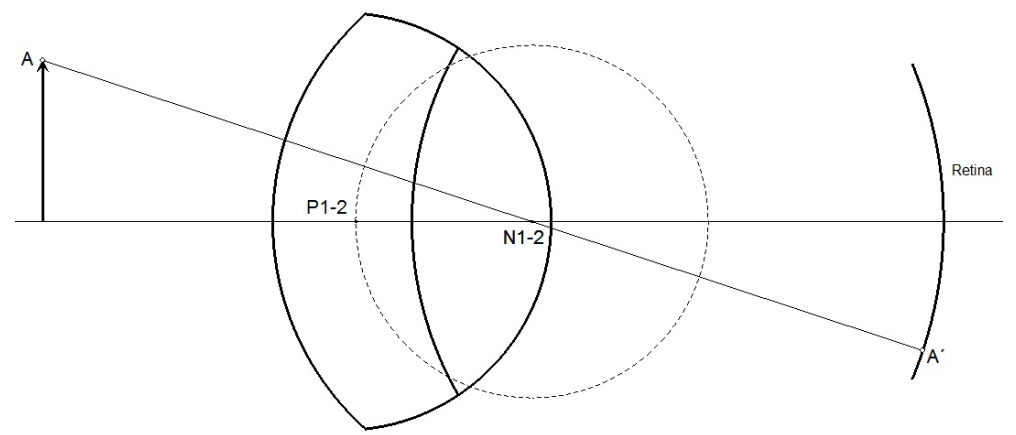

Figura 18: Ojo reducido de Listing 


\section{Conclusiones}

Hemos sugerido que el reconocimiento de la comparación del ojo con una cámara obscura demandaba la solución de tres dificultades centrales: ¿cómo se forman imágenes a través de agujeros?; ¿cómo se comporta la luz al atravesar una esfera transparente? y precisar el protagonismo de la retina. En el artículo señalamos que Kepler resolvió los tres problemas. Hemos mostrado que con el apego a las analogías geométricas, concebidas como instrumentos de papel, y con la firme decisión de arriesgar aproximaciones para omitir lo accidental mientras se mantiene incólume lo esencial, Kepler logró compensar los errores inducidos por el hecho de valerse de una ley de la refracción que no armonizaba con la información empírica disponible. Mostramos que el uso de los diagramas demanda un esfuerzo por concebir modificaciones cinéticas. Mostramos también que, así como la tradición moderna acogió las leyes celestes de Kepler al lograr armonizarlas con los principios de la mecánica moderna, ignorados por Kepler, de la misma forma, los estudiosos de la óptica moderna abrazaron el teorema fundamental al lograr armonizarlo con la ley de Snell-Descartes.

\section{Referencias}

En paréntesis cuadrados se mencionan, en unos casos, abreviaturas para citar, en otros, el año de la edición original.

Alhacén. 2001. De Aspectibus (I-III) [Aspectibus]. Trad A. M. Smith. Philadelphia: American Philosophical Society.

Aristóteles. 2004. Problemas. Trad. Ester Sánchez Millán. Madrid: Editorial Gredos.

Borrelli, A. 2017. Optical Diagrams as "Paper Tools": Della Porta's Analysis of Biconvex Lenses from De refractione to De telescopio. En: A. Borrelli, G. Hon y Y. Zik (eds.), The Optics of Giambattista Della Porta (ca. 1535-1615): A Reassessment. New York: Springer, pp.57-96.

Buchdahl, G. 1972. Methodological Aspects of Kepler's Theory of Refraction. Studies in History and Philosophy of Sciences 3: 265-298.

Cardona, C. 2016. Kepler: Analogies in thesearch for the law of refraction. Studies in History and Philosophy of Science 59: 22-35.

Cardona, C. 2020. La pirámide visual: evolución de un instrumento conceptual. Bogotá: Editorial Universidad del Rosario.

Cardona C. y Gutiérrez, J. 2020. The Law of Refraction and Kepler's Heuristic. Archive for History of Exact Sciences 74(1): 45-75.

Chen-Morris, R. 2009. From emblems to diagrams: Kepler's new pictorial language of scientific representations. Renaissance Quarterly 62(1): 134-70.

Crombie, A. C. 1964. Early Concepts of the Senses and the Mind. Scientific American 210(5): 108-16.

Dupré, S. 2007. Playing with images in a Dark Room Kepler's Ludi inside the Camera Obscura. En: W. Lefèvre (ed.), Inside the Camera Obscura - Optics and Art under the Spell of the Projected Image. Berlin: Max-Planck-Intitut für Wissenschafts Geschichte, pp.59-73. 
Field, J. 1986. Two Mathematical Inventions in Kepler's Ad Vitellionem Paralipomena. Studies in History and Philosophy of Sciences 17(4): 449-68.

Gentner, D. 2002. Analogy in Scientific Discovery: The Case of Johannes Kepler. En: L. Magnani \& N. J. Nersessian (eds.), Model-based Reasoning: Science, Technology, Values. New York: Kluwer Academic, pp.21-39.

Giardino, V. 2017. Diagrammatic Reasoning in Mathematics. En: L. Magnani y T. Bertolotti (eds.) Springer Handbook of Model Based Science. New York: Springer, pp.499-521.

Grant, E. (edit.). 1974. A Source Book in Medieval Science. Cambridge (Mass): Harvard University Press.

Heeffer, A. 2017. Using Invariances in Geometrical Diagrams: Della Porta, Kepler and Descartes on Refraction. En: A. Borrelli, G. Hon y Y. Zik (eds.), The Optics of Giambattista Della Porta (ca. 1535-1615): A Reassessment. New York: Springer, pp.145-68.

Helmholtz, H. 2005 [1909]. Treatise on Physiological Optics (Volúmenes 1, 2 y 3). Mineola: Dover Publications, Inc. Trad. James P. C. Southhall.

Holton, G. 1973. Johannes Kepler's Universe: its Physics and Metaphysycs. En: Thematic Origins of Scientific Thought Kepler to Einstein. Cambridge (Mass): Harvard University Press, pp.69-90.

Itard, J. (1957). Les lois de la refraction de la lumiere chez Kepler. Revue d'histoire des sciences et de leurs applications 10(1): 59-68.

Kepler, J. 2000 [1604]. [Paralipomena]. Optics: Paralipomena to Witelo \& Optical Part of Astronomy. Santa Fe: Green Lion Press. Trad. William H. Donahue.

Kepler, J. 1939 [1604]. [GW]. Ad Vitellionem Paralipomena Quibus Astronomiae pars Optica traditur. En: Gesammelte Werke [GW], vol II; München: C. H. Beck'sche Verlagsbuchhandlung; ed. and comm. Franz Hammer.

Kepler, J. 2008 [1611]. Dioptrik. En: Schriften zur Optik. Frankfurt: Verlag Harri Deutch pp.443-525.

Lindberg, D. 1970. A reconsideration of Roger Bacon's Theory of Pinhole Images. Archive for History of Exact Sciences 6(3): 214-23.

Lindberg, D. C. 1976. Theories of Vision from Al-Kindi to Kepler. Chicago: The University of Chicago Press.

Lohne, J. 1968. Der eigenartige Einfluß Witelos auf die Entwicklung der Dioptrik. Archive for History of Exact Sciences. 4: 414-26.

Malebranche, N. 2009 [1712]. Acerca de la investigación de la verdad. Salamanca: Ediciones Sígueme.

Malet, A. 1990. Keplerian Illusions: Geometrical Pictures vs Optical Images in Kepler's Visual Theory. Studies in History and Philosophy of Sciences 21(1): 1-40.

Peirce, Ch. S. 1985. Johann Kepler. En: C. Eisele (Ed.), Historical Perspectives on Peirce's Logic of Science. A History of Science, parte i. Berlín: Mouton Publishers, pp.290-5.

Platter, F. 1583. De partis corporis humani structura et usu libri III. Basel.

Ptolomeo. trad. en 1996. Optics. En: A. Mark Smith (Edit. y Trad.), Ptolemy's Theory of Visual Perception. Philadelphia: The American Philosophical Society, pp.67-261.

Raynaud, D. 2016. A Critical Edition of Ibn al-Haytham's On the Shape of the Eclipse. Cham: Springer Verlag.

Risner, F. (edit.). 1572. Opticae thesaurus Alhazeni Arabis libri septem...Item Vitellonis Thuringopoloni libri decem. Basile: Per episcopios. 
Sabra, A. 2007. Alhazen's Optics in Europe: Some Notes on What It said and What It Did Not Say. En W: Lefèvre (edit.), Inside the Camera Obscura - Optics and Art under the Spell of the Projected Image. Berlin: Max-Planck-Intitut für Wissenschafts Geschichte, pp.53-57.

Shapiro, A. 2007. Images: Real and Virtual, Projected and Perceived, from Kepler to Dechales. En W. Lefèvre (edit.), Inside the Camera Obscura - Optics and Art under the Spell of the Projected Image. Berlin: Max-Planck-Intitut für Wissenschafts Geschichte, pp.75-94.

Straker, S. 1971. Kepler's Optics: A Study in the Development of Seventeenth Century Philosophy. (Tesis doctoral). Universidad de Indiana, Bloomington.

Straker, S. 1981. Kepler, Tycho, and the 'Optical Part of Astronomy': the Genesis of Kepler's Theory of Pinhole Images. Archives for History of Exact Sciences, 24(4): 267-93.

Voelkel, J. R. 2001. The Composition of Kepler's Astronomia nova. Pinceton: Princeton University Press.

Weber, E., D. Wouters \& J. Meheus (ed.). Logic, Reasoning and Rationalit. Dordrecht: Springer, pp.59-76.

\section{Notas}

${ }^{1}$ Un estudio detallado de los errores - a la luz de la física moderna- en la heurística kepleriana a propósito de la mecánica celeste puede seguirse en J. Voelkel (2002) y en G. Holton (1973).

${ }^{2}$ Una semblanza del uso de analogías en la obra de Kepler puede seguirse en D. Gentner (2002).

${ }^{3}$ Esta es también la perspectiva que defiende Alistair C. Crombie (1964).

${ }^{4}$ A propósito de la distinción, el lector puede seguir los excelentes trabajos de Raz ChenMorris (2009); Alan Shapiro (2007) y Antoni Malet (1990).

${ }^{5}$ Un seguimiento completo del programa de investigación puede seguirse en C. Cardona (2020).

${ }^{6}$ Véase la carta de Tycho a Maestlin informándole acerca de la dificultad en Stephen Straker, 1971, p.5. Straker también ofrece una excelente reseña de los trabajos de Tycho con cámaras obscuras y evalúa los errores en los que incurre el astrónomo danés (1981).

${ }^{7}$ Una reseña completa puede seguirse en Lindberg, 1970.

${ }^{8}$ Usaremos la sigla $G W$ para referirnos a la edición de las obras completas.

${ }^{9} \mathrm{El}$ lector puede remitirse a la edición que Dominique Raynaud ha preparado del texto de Alhacén. La edición no sólo ofrece un reporte histórico detallado de la evolución primitiva de la cámara obscura, también se esfuerza por presentar los argumentos de Alhacén en un lenguaje asequible al lector contemporáneo; cfr. Raynaud, 2016. De acuerdo a las pesquisas adelantadas por A. I. Sabra, la primera descripción en la tradición árabe de una pintura proyectada en un cuarto obscuro se encuentra en la segunda mitad del siglo xiii en The Commentary or Revision/Tanqīh of Alhazen's optics de Kamāl al-Dīn al-Fārisī (2007, p.54).

${ }^{10}$ Witelo tomó los datos de Ptolomeo excepto por una diferencia en la primera línea. Itard sostiene que Kepler corrigió la desviación reportada en la primera línea para que fuese coherente con el ángulo de refracción copiado (1957, p.60). Edward Grant advierte que las ediciones impresas de la Perspectiva de Witelo presentan en la primera línea un ángulo de $7^{\circ} 45^{\prime}$; sin embargo, el comentarista revisó tres manuscritos previos en los que aparece en la primera 
línea $7^{\circ} 55^{\prime}$ (1974, p.425, nota b de la tabla 1). Kepler debió corregir, más bien, el ángulo de refracción y no la desviación (comparar con Tabla 2). Lohne sostiene que Kepler encontró dos años después de la publicación de los Paralipomena, gracias a los trabajos de Thomas Harriot (1560-1621), los aspectos dudosos de los datos de Witelo (1968, pp.414-26).

${ }^{11}$ Para ver qué tipo de correspondencia falló con las dos primeras familias y cómo habría sido posible que la metodología de Kepler condujese a la Ley de Snell-Descartes, véase C. Cardona y J. Gutiérrez (2020). El artículo muestra el uso de diagramas complementados con variaciones cinéticas.

${ }^{12}$ En caso de que el segundo medio sea de menor densidad, el segundo componente tendría que ser proporcional a la secante del ángulo de incidencia (Paralipomena, IV, p.126; GW, p.107).

${ }^{13}$ Un seguimiento detallado de la heurística kepleriana en relación con la ley de la refracción propuesta se encuentra en C. Cardona (2016). El término $k$ alude a una contante de proporcionalidad que depende de las densidades ópticas de los medios involucrados.

${ }^{14}$ Una presentación completa de la descripción anatómica que acoge Kepler puede seguirse en D. Lindberg (1976, pp.188-93).

${ }^{15}$ Kepler acopió poderosos argumentos para resistir el principio clásico de formación de imágenes a través de espejos o dispositivos que refractan la luz (Paralipomena, III, pp.73-91; $G W$, pp.40-60). Según tal protocolo, formulado inicialmente por Euclides, elevado a la categoría de principio por Ptolomeo y acogido posteriormente por Alhacén, la imagen producida por una fuente puntual se recoge en la intersección de la prolongación del rayo reflejado o refractado y la normal a la superficie, o a la interfase de dos medios, trazada desde el objeto (Ptolomeo, trad. en 1996, III § 3). Kepler propuso en su remplazo el siguiente principio: «el lugar genuino de la imagen es el punto en el cual se reúnen los rayos visuales [reflejados o refractados] que se extienden desde los ojos más allá de los puntos de reflexión o de refracción» (Paralipomena, III, p.85; GW, p.53).

${ }^{16}$ Para un seguimiento de la crítica de Kepler, acogiendo el resultado que aquí comentamos, a la manera como Giambattista della Porta (1535-1615) presenta la formación de imágenes en una cámara obscura, véase S. Dupré (2007, p.70).

${ }^{17}$ Para un estudio de los artificios presentes en dicho teatro véase S. Dupré (2007).

${ }^{18}$ En otro lugar sostiene Kepler: «Una imagen [imago] es en parte una creatura de intención [partim intentionale ens]» (Paralipomena, V, p.193; GW, p.163).

${ }^{19}$ Ptolomeo formuló la reversibilidad mencionada (trad. en 1996, V, p.235). Kepler cita como fuente de dicho principio la proposición 9 del libro X de Witelo (Risner, 1572, pp.41314).

${ }^{20} \mathrm{Si}$ se usa la ley de Snell-Descartes, el ángulo equivale a $48^{\circ} 45^{\prime}$ para el paso de aire a agua.

${ }^{21}$ Las figuras respetan las expectativas de refracción de Snell-Descartes (para un índice de refracción: 1.1). Ya anotamos, sin embargo, que para ángulos pequeños las expectativas de Snell-Descartes y Kepler se aproximan. Para ángulos mayores, Kepler espera refracciones aún mayores. No obstante, el comportamiento cualitativo es semejante. Si el lector se vale de las modelaciones, allí puede alterar a su antojo el índice de refracción.

${ }^{22}$ En consecuencia, los ángulos $A G B, B G C, C G D$ también son congruentes y la amplitud de cada uno de ellos es la mitad de la amplitud de $A F B$.

${ }^{23}$ Dado que $M B$ es paralelo a $L A$, la diferencia entre el rayo refractado y el incidente coincide 
con el ángulo entre el rayo refractado y la recta $L A$. Lo mismo vale para el rayo NC.

${ }^{24}$ Recordemos que, según la ley de Kepler, los incrementos de $d_{2}$ crecen como lo hace la secante de $r$.

${ }^{25}$ En C. Cardona y J. Gutiérrez (2020) hemos mostrado que, si se sigue la heurística de Kepler, se puede hallar una hipérbola representativa para cada par de medios con densidades ópticas diferentes. También exploramos la riqueza de la manipulación cinética de los diagramas keplerianos.

${ }^{26}$ Helmholtz mostró que se trata efectivamente de una envolvente hiperbólica (2005 [1909], vol.1, p.66).

${ }^{27}$ El filósofo se valió de estos resultados para calcular a qué distancia, con respecto al fondo del cristalino, debe estar la retina para recoger fielmente la pintura de un objeto que se ubica a 2 pies del observador (2009 [1712], pp.906-7).

${ }^{28}$ En un sistema óptico centrado, las superficies esféricas, que limitan los diferentes medios transparentes del sistema, tienen sus centros distribuidos a lo largo de una línea recta (eje óptico). El complejo ocular es un sistema óptico centrado que consta de cuatro superficies cuasiesféricas y cinco medios interpuestos: aire, superficie anterior de la córnea, córnea, superficie posterior de la córnea, humor acuoso, superficie anterior del lente cristalino, humor cristalino, superficie posterior del lente cristalino y, finalmente, humor vítreo.

${ }^{29}$ Helmholtz demostró, por inducción, que esos seis puntos siempre existen y son únicos para cada sistema (2005 [1909], vol. 1, pp.64-80).

${ }^{30} P_{1-2}$ es el punto medio de los dos puntos principales.

\section{Agradecimientos}

Agradezco a la División de Investigaciones e Innovación de la Universidad del Rosario por el apoyo prestado al desarrollo de la presente investigación. 